\title{
A triclinic polymorph of benzanilide: disordered molecules form hydrogen-bonded chains
}

Katharine F. Bowes, Christopher Glidewell, John N. Low, Janet M. S. Skakle and James L. Wardell 
Acta Crystallographica Section C

\section{Crystal Structure}

Communications

ISSN 0108-2701

\section{A triclinic polymorph of benzanilide: disordered molecules form hydrogen- bonded chains}

\author{
Katharine F. Bowes, ${ }^{\text {a }}$ Christopher Glidewell, ${ }^{a *}$ John N. \\ Low, $^{\text {b Janet M. S. Skakle }}{ }^{\mathrm{b}}$ and James L. Wardell ${ }^{\mathrm{C}}$ \\ ${ }^{a}$ School of Chemistry, University of St Andrews, St Andrews, Fife KY16 9ST, \\ Scotland, 'b Department of Chemistry, University of Aberdeen, Meston Walk, \\ Old Aberdeen AB24 3UE, Scotland, and 'Instituto de Química, Departamento de \\ Química Inorgânica, Universidade Federal do Rio de Janeiro, 21945-970 Rio de \\ Janeiro, RJ, Brazil \\ Correspondence e-mail: cg@st-andrews.ac.uk
}

Received 28 October 2002

Accepted 1 November 2002

Online 10 December 2002

In the $P \overline{1}$ polymorph of benzanilide or $N$-phenylbenzamide, $\mathrm{C}_{13} \mathrm{H}_{11} \mathrm{NO}$, the molecules are linked into simple $C(4)$ chains by $\mathrm{N}-\mathrm{H}$...O hydrogen bonds. The molecules exhibit orientational disorder, but the donor and acceptor in a given hydrogen bond may occur, independently, in either the major or the minor orientation, such that all four possible $\mathrm{N}-\mathrm{H} \cdots \mathrm{O}$ combinations have very similar geometries. The structure of this $P \overline{1}$ polymorph can be related to that of a previously reported $C 2 / c$ polymorph.

\section{Comment}

The crystal structure of benzanilide, $\mathrm{PhNHCOPh}$, (I), was first reported many years ago (Kashino et al., 1979). These authors reported an ambient temperature study of a $C 2 / c$ phase crystallized from ethanol, which has $Z^{\prime}=\frac{1}{2}$ with the molecules disordered across twofold rotation axes, such that the $\mathrm{O}$ atom and the $\mathrm{H}$ atom bonded to $\mathrm{N}$ both lie on the twofold axes. $\mathrm{A}$ unique $\mathrm{H} \cdots \mathrm{O}$ contact thus characterizes the $\mathrm{N}-\mathrm{H} \cdots \mathrm{O}$ hydrogen bonds, which link the molecules into a $C(4)$ chain generated by translation along the shortest axis of the cell, viz. $b=5.323$ (3) ̊.

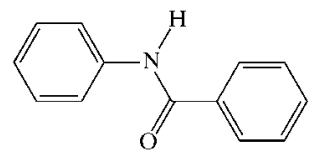

(I)

In this paper, we report the structure of a triclinic $(P \overline{1}$, $Z^{\prime}=1$ ) polymorph of (I), also crystallized from ethanol. In this polymorph, the molecules (Fig. 1) lie in general positions, but it was clear early in the refinement that there was some orientational disorder in the structure. Some $16 \%$ of the molecular sites are occupied by a second orientation, which is approximately related to the major orientation by a $180^{\circ}$ rotation of the molecule about a line in the plane of the central HNCO unit lying normal to the C14...C24 line. Hence atoms $\mathrm{C} 14$ and $\mathrm{C} 44$ have almost coincident sites, as do atoms C24 and C34. Similarly, atom pairs O11/O21 and H11/ H21 occupy sites which are almost coincident (Fig. 2).

The molecules of (I) are linked into $C(4)$ chains generated by translation along the [100] direction (Fig. 3), and because of the close proximity of the alternative donor and acceptor sites, hydrogen bonds can be formed between any two adjacent molecules within the chain, regardless of whether they adopt the major or minor orientation (Table 2). Hence the hydrogen bonding imposes no necessary correlation between the molecular orientations at adjacent sites within the chain, although this may be imposed by non-bonded C $\cdots$ C contacts.

Within the molecule of (I), the bond lengths and angles present no unusual features. The central $\mathrm{C}-\mathrm{N}(\mathrm{H})-\mathrm{C}(\mathrm{O})-\mathrm{C}$ fragment is essentially planar and the phenyl rings are each

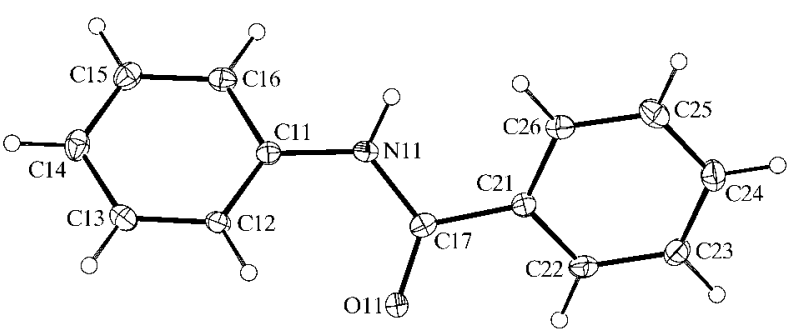

(a)

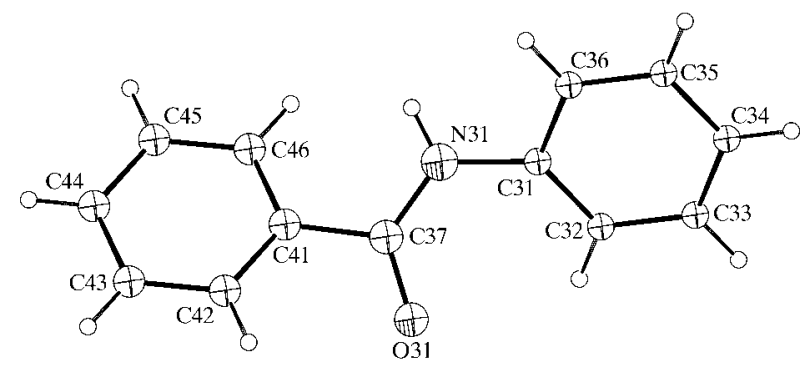

Figure 1

(b)

Views of the molecule of compound (I), showing the atom-labelling scheme for $(a)$ the major orientation and $(b)$ the minor orientation. For the major orientation, displacement ellipsoids are drawn at the $30 \%$ probability level, but for the minor orientation, all non- $\mathrm{H}$ atoms were refined isotropically (see text). $\mathrm{H}$ atoms are shown as small spheres of arbitrary radii.

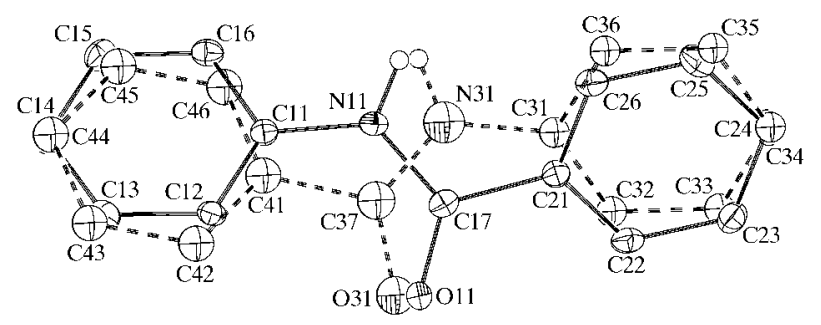

Figure 2

Part of the crystal structure of (I), showing the two orientations of the molecule; the major orientation is shown with solid bonds and the minor orientation with dashed bonds. 
twisted by $\mathrm{ca} 30^{\circ}$ away from this plane (Table 1 ). The conformation in the $P \overline{1}$ polymorph thus resembles that in the $C 2 / c$ polymorph, where the dihedral angles between the rings and the central unit are both $\mathrm{ca} 31^{\circ}$.

The density reported for the $C 2 / c$ polymorph $\left(1.321 \mathrm{Mg} \mathrm{m}^{-3}\right)$ is somewhat lower than that found here for the $P \overline{1}$ form. This suggests that the $P \overline{1}$ form may be thermodynamically more stable (Burger \& Ramberger, 1979). The ambient-temperature unit cell reported for the $C 2 / c$ poly-

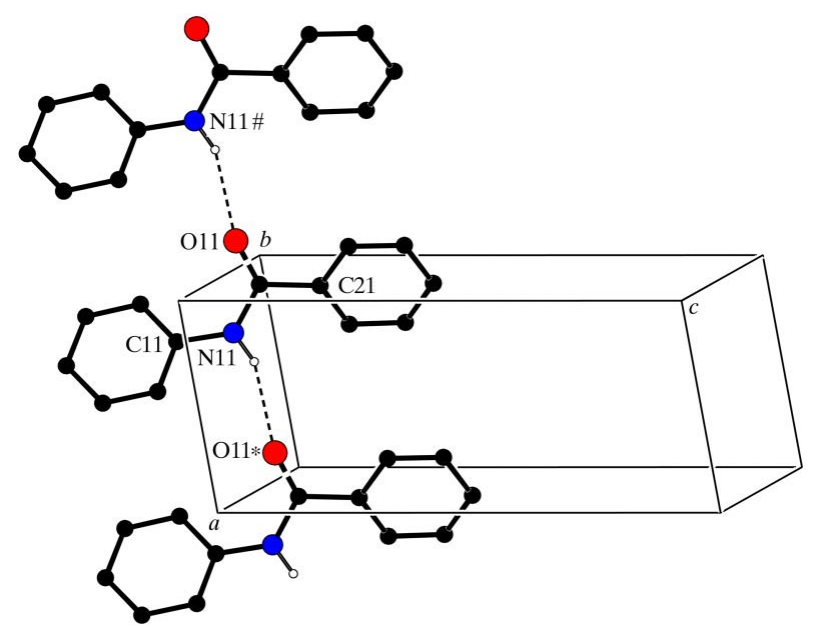

Figure 3

Part of the crystal structure of (I), showing the formation of a $C(4)$ chain along [100]. For the sake of clarity, only the major orientation is shown and $\mathrm{H}$ atoms bonded to $\mathrm{C}$ atoms have been omitted. Atoms marked with an asterisk $(*)$ or hash (\#) are at the symmetry positions $(1+x, y, z)$ and $(x-1, y, z)$, respectively.
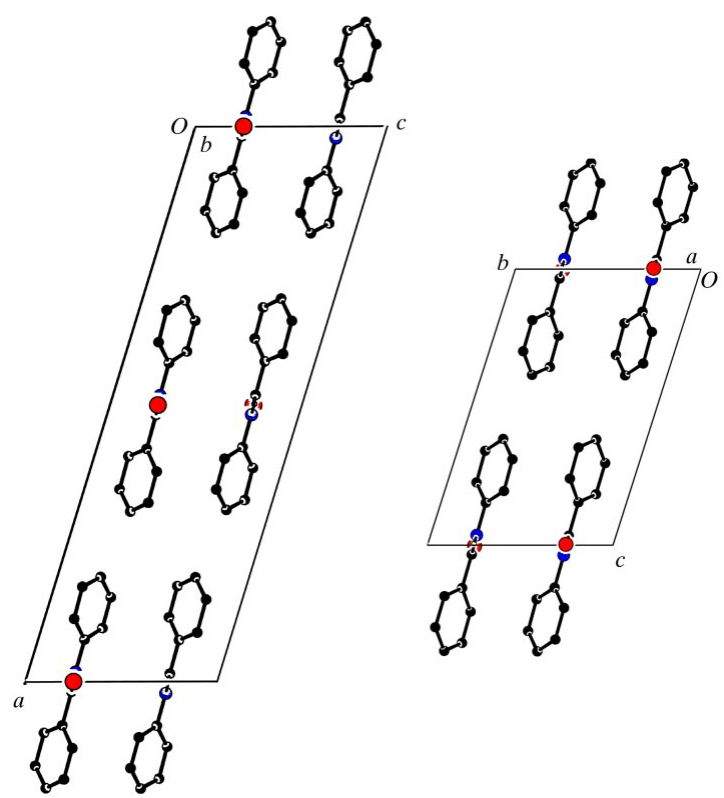

Figure 4

Projections of the structures of (I), showing (a) the $P \overline{1}$ polymorph projected on to the $b c$ plane (for the sake of clarity, only the major orientation is shown), and (b) the $C 2 / c$ polymorph, projected on to the $a c$ plane (for the sake of clarity, only one orientation is shown). In each projection, $\mathrm{H}$ atoms bonded to $\mathrm{C}$ atoms have been omitted for clarity. morph $[a=24.34$ (4), $b=5.325$ (3) and $c=8.012$ (8) $\AA$, and $\beta=$ $107.2(3)^{\circ}$; Kashino et al., 1979] can be readily related to the $P \overline{1}$ cell by the transformation $\left(0,-1,0 / 0,0,-1 / \frac{1}{2}, 0,0\right)$. In the $C 2 / c$ polymorph, the molecules lie across twofold rotation axes, with the centroid of the reference molecule at $(0,0.205,0.250)$, while in the $P \overline{1}$ polymorph, the centroid of the reference molecule is at approximately $(0.198,0.749,-0.002)$, so that the projections of the two structures down their short axes are very similar (Fig. 4). However, alternate chains in the [100] direction in the $C 2 / c$ structure are related by the $C$-centring operation and hence suffer a shift of $\frac{b}{2}$ between adjacent chains in this direction, whereas no such shifts occur in the $P \overline{1}$ polymorph.

In addition to these translations, the very different disorder ratios (50:50 in $C 2 / c$ and 84:16 in $P \overline{1})$ effectively preclude the possibility of a simple displacive phase transformation between the two polymorphs, as this would require at least $34 \%$ of the molecules to change orientation on conversion of either phase to the other. Since the molecules are $c a 11.2 \AA$ in length, and longer if the van der Waals surfaces are included, the end-over-end rotation involved in this change of orientation would require each such molecule to sweep out, unhindered, a disc of area nearly $100 \AA^{2}$.

As in the $P \overline{1}$ polymorph, there is no necessary correlation between the orientations of adjacent molecules in the $C 2 / c$ polymorph imposed by the hydrogen bonding. However, it was found by Kashino et al. (1979) that non-bonded C...C contacts imposed correlation within, but not between, the [010] chains. Kashino et al. (1979) discussed the $C 2 / c$ structure in terms of the fully ordered structures which could arise in each of the subgroups of $C 2 / c\left(C c, C \overline{1}, P 2_{1} / c\right.$ and $\left.P 2_{1} / n\right)$; the representation in Fig. $4(b)$ is, in fact, the $C \overline{1}$ substructure.

In our recent structural studies, we have encountered several examples of concomitant polymorphism. Thus, when crystallized from ethanol, 2-iodo-4-nitroaniline yields a mixture of triclinic $\left(P \overline{1}, Z^{\prime}=1\right)$ and orthorhombic $\left(P b c a, Z^{\prime}=1\right)$ crystals which have slightly different colours (McWilliam et al., 2001). Crystallization of ethyl $N$-(2-amino-6-benzyloxy-5nitrosopyrimidin-2-yl)-3-aminopropanoate from acetonitrileethanol-water (1:1:1 by volume) yields a mixture of two monoclinic polymorphs, one blue $\left(P 2_{1} / c, Z^{\prime}=1\right)$ and the other pink $\left(P 2_{1}, Z^{\prime}=2\right)$ (Quesada et al., 2002), where the conformations of the three independent molecules are all different, so that these concomitant polymorphs are also conformational polymorphs. The 1:1 adduct formed between $(S)$-malic acid and $4,4^{\prime}$-bipyridyl crystallizes from methanol as a mixture of triclinic $\left(P 1, Z^{\prime}=1\right)$ and monoclinic $\left(C 2, Z^{\prime}=1\right)$ polymorphs (Farrell et al., 2002). Finally, benzanilide crystallizes from ethanol in both a monoclinic form $\left(C 2 / c, Z^{\prime}=\frac{1}{2}\right.$; Kashino et al., $1979)$ and the triclinic form $\left(P \overline{1}, Z^{\prime}=1\right)$ reported here.

We emphasize that in none of these systems had there been any attempt to engineer such polymorphic behaviour, nor was this behaviour being specifically sought after. Instead, each pair of polymorphs was identified serendipitously. In the cases of 2-iodo-4-nitroaniline and the nitrosopyrimidine, the identification of the two forms was facilitated by their different colours, but in the other examples, identification depended 
solely upon careful scrutiny of the crystalline samples and the observation of more than one crystal habit, followed in every case by careful manual separation.

Our identification, essentially by chance, of four such examples within a rather short space of time suggests to us that the phenomenon of concomitant polymorphism may, in fact, be a rather common one, certainly far more common than the current literature [for a review, see Bernstein et al. (1999)] tends to suggest, but one which goes largely unnoticed. On the other hand, we note the recent report on 3,6,13,16-tetrabromo-2,7,12,17-tetrapropylporphycene, where monoclinic prisms and triclinic plates crystallize concurrently from dichloromethane-hexane (Aritome et al., 2002).

\section{Experimental}

A commercial sample of benzanilide (Aldrich) was crystallized from an ethanol solution at ambient temperature.

$\begin{array}{ll}\text { Crystal data } & \\ \mathrm{C}_{13} \mathrm{H}_{11} \mathrm{NO} & Z=2 \\ M_{r}=197.23 & D_{x}=1.359 \mathrm{Mg} \mathrm{m}^{-3} \\ \text { Triclinic, } P \overline{1} & \text { Mo } K \alpha \text { radiation } \\ a=5.3406(5) \AA & \text { Cell parameters from } 2140 \\ b=7.7727(7) \AA & \text { reflections } \\ c=12.3901(15) \AA & \theta=3.5-27.5^{\circ} \\ \alpha=72.702(3)^{\circ} & \mu=0.09 \mathrm{~mm}^{-1} \\ \beta=79.389(3)^{\circ} & T=120.0(1) \mathrm{K} \\ \gamma=89.914(5)^{\circ} & \text { Block, colourless } \\ V=481.89(9) \AA^{3} & 0.08 \times 0.06 \times 0.04 \mathrm{~mm}\end{array}$

\section{Data collection}

Nonius KappaCCD area-detector diffractometer

$\varphi$ scans, and $\omega$ scans with $\kappa$ offsets

Absorption correction: multi-scan

(DENZO-SMN; Otwinowski \&

Minor, 1997)

$T_{\min }=0.989, T_{\max }=0.997$

7033 measured reflections

\section{Table 1}

Selected torsion angles $\left({ }^{\circ}\right)$.

\begin{tabular}{lrrr}
\hline $\mathrm{C} 11-\mathrm{N} 11-\mathrm{C} 17-\mathrm{C} 21$ & $-179.8(3)$ & $\mathrm{N} 11-\mathrm{C} 17-\mathrm{C} 21-\mathrm{C} 22$ & $-150.7(3)$ \\
$\mathrm{C} 12-\mathrm{C} 11-\mathrm{N} 11-\mathrm{C} 17$ & $32.5(5)$ & & \\
\hline
\end{tabular}

\section{Table 2}

Hydrogen-bonding geometry $\left(\AA{ }^{\circ},{ }^{\circ}\right.$.

\begin{tabular}{lllll}
\hline$D-\mathrm{H} \cdots A$ & $D-\mathrm{H}$ & $\mathrm{H} \cdots A$ & $D \cdots A$ & $D-\mathrm{H} \cdots A$ \\
\hline $\mathrm{N} 11-\mathrm{H} 11 \cdots \mathrm{O} 11^{\mathrm{i}}$ & 0.88 & 2.31 & $3.141(4)$ & 157 \\
$\mathrm{~N} 11-\mathrm{H} 11 \cdots \mathrm{O} 31^{\mathrm{i}}$ & 0.88 & 2.34 & $3.13(2)$ & 150 \\
$\mathrm{~N} 31-\mathrm{H} 31 \cdots \mathrm{O} 11^{\mathrm{i}}$ & 0.88 & 2.31 & $3.17(3)$ & 165 \\
$\mathrm{~N} 31-\mathrm{H} 31 \cdots \mathrm{O} 31^{\mathrm{i}}$ & 0.88 & 2.37 & $3.24(3)$ & 172 \\
\hline
\end{tabular}

Symmetry code: (i) $1+x, y, z$.

2140 independent reflections 1092 reflections with $I>2 \sigma(I)$

$R_{\text {int }}=0.079$

$\theta_{\max }=27.5^{\circ}$

$h=-6 \rightarrow 6$

$k=-10 \rightarrow 10$

$l=-15 \rightarrow 15$

\section{Refinement}

Refinement on $F^{2}$ $R\left[F^{2}>2 \sigma\left(F^{2}\right)\right]=0.061$ $w R\left(F^{2}\right)=0.160$ $S=0.96$

2140 reflections

159 parameters

$$
\begin{aligned}
& \text { H-atom parameters constrained } \\
& w=1 /\left[\sigma^{2}\left(F_{o}^{2}\right)+(0.0761 P)^{2}\right] \\
& \text { where } P=\left(F_{o}^{2}+2 F_{c}^{2}\right) / 3 \\
& (\Delta / \sigma)_{\max }<0.001 \\
& \Delta \rho_{\max }=0.27 \mathrm{e} \AA^{-3} \\
& \Delta \rho_{\min }=-0.25 \AA^{-3}
\end{aligned}
$$

Space group $P \overline{1}$ was selected and confirmed by the subsequent structure analysis. The ADDSYM option in PLATON (Spek, 2002) revealed no additional symmetry. For the minor orientational component, the two rings were constrained to be planar regular hexagons, with $\mathrm{C}-\mathrm{C}$ distances of $1.39 \AA$, and the remaining distances involving $\mathrm{C}, \mathrm{N}$ and $\mathrm{O}$ atoms were tied to the corresponding distances in the major component. The non- $\mathrm{H}$ atoms in the minor component were all refined isotropically. A common isotropic displacement parameter was applied to atoms $\mathrm{C} 31-\mathrm{C} 36$, a second common isotropic displacement parameter to atoms $\mathrm{C} 41-\mathrm{C} 46$, and individual isotropic parameters to atoms N31, C37 and O31. The site-occupancy factors for the two orientations then refined to 0.839 (5) and 0.161 (5). The $\mathrm{H}$ atoms were treated as riding, with $\mathrm{C}-\mathrm{H}$ distances of $0.95 \AA$ and $\mathrm{N}-\mathrm{H}$ distances of $0.88 \AA$.

Data collection: KappaCCD Server Software (Nonius, 1997); cell refinement: $D E N Z O-S M N$ (Otwinowski \& Minor, 1997); data reduction: $D E N Z O-S M N$; program(s) used to solve structure: SHELXS97 (Sheldrick, 1997); program(s) used to refine structure: SHELXL97 (Sheldrick, 1997); molecular graphics: PLATON (Spek, 2002); software used to prepare material for publication: SHELXL97 and PRPKAPPA (Ferguson, 1999).

The X-ray data were collected at the EPSRC X-ray Crystallographic Service, University of Southampton, England; the authors thank the staff for all their help and advice. JNL thanks NCR Self-Service, Dundee, for grants which have provided computing facilities for this work. JLW thanks CNPq and FAPERJ for financial support.

Supplementary data for this paper are available from the IUCr electronic archives (Reference: SK1598). Services for accessing these data are described at the back of the journal.

\section{References}

Aritome, I., Shimakoshi, H. \& Hisaeda, Y. (2002). Acta Cryst. C58, o563-o564. Bernstein, J., Davey, R. J. \& Henck, J.-O. (1999). Angew. Chem. Int. Ed. 38, 3440-3461.

Burger, A. \& Ramberger, R. (1979). Mikrochim. Acta, 2, 259-271.

Farrell, D. M. M., Ferguson, G., Lough, A. J. \& Glidewell, C. (2002). Acta Cryst. B58, 530-544.

Ferguson, G. (1999). PRPKAPPA. University of Guelph, Canada.

Kashino, S., Ito, K. \& Haisa, M. (1979). Bull. Chem. Soc. Jpn, 52, 365-369.

McWilliam, S. A., Skakle, J. M. S., Low, J. N., Wardell, J. L., Garden, S. J., Pinto, A. C., Torres, J. C. \& Glidewell, C. (2001). Acta Cryst. C57, 942-945.

Nonius (1997). KappaCCD Server Software. Windows 3.11 Version. Nonius BV, Delft, The Netherlands.

Otwinowski, Z. \& Minor, W. (1997). Methods in Enzymology, Vol. 276, Macromolecular Crystallography, Part A, edited by C. W. Carter Jr \& R. M. Sweet, pp. 307-326. New York: Academic Press.

Quesada, A., Marchal, A., Melguizo, M., Nogueras, M., Sánchez, A., Low, J. N., Cannon, D., Farrell, D. M. M. \& Glidewell, C. (2002). Acta Cryst. B58, 300315.

Sheldrick, G. M. (1997). SHELXS97 and SHELXL97. University of Göttingen, Germany.

Spek, A. L. (2002). PLATON. Version of June 2002. University of Utrecht, The Netherlands. 